\title{
ESTADO DO CONHECIMENTO DA TEMÁTICA RELAÇÃO PÚBLICO E PRIVADO NOS PROGRAMAS DE PÓS-GRADUAÇÃO STRICTU SENSO EM EDUCAÇÃO NO BRASIL
}

\author{
ESTADO DE CONOCIMIENTO DEL TEMA RELACIONES PÚBLICAS Y PRIVADAS \\ EN PROGRAMAS DE POSTGRADO STRICTU SENSO EN EDUCACIÓN EN BRASIL
}

\author{
STATE OF KNOWLEDGE OF PUBLIC AND PRIVATE RELATIONS IN BRAZILIAN \\ POSTGRADUATION PROGRAMS IN EDUCATION
}

\author{
Marina Silveira Bonacazata SANTOS ${ }^{1}$ \\ Jani Alves da Silva MOREIRA ${ }^{2}$
}

\begin{abstract}
RESUMO: O presente texto tem como objetivo apresentar um mapeamento por meio do Estado do Conhecimento referente ao tema "Relação Público-Privado" na Educação (RPPE) em dissertações de mestrado e teses de doutorado desenvolvidos nos Programas de Pós-Graduação em Educação (PPGEs) do Brasil, no período 1994 a 2018. Trata-se de uma pesquisa exploratória e qualitativa no qual objetivou-se também compreender a avaliação atribuída pela Coordenação de Aperfeiçoamento de Pessoal de Nível Superior (CAPES) aos PPGEs brasileiros no quadriênio 2013-2016, além de perceber, o crescimento do estudo da temática RPPE na pós-graduação brasileira a fim de verificar algumas lacunas quanto a configuração das produções sobre a temática em questão.
\end{abstract}

PALAVRAS-CHAVE: Estado da arte. Estado do conhecimento. Relação público e privado. Programa de pós-graduação em educação. Brasil.

RESUMEN: Este artículo tiene como objetivo presentar un mapeo a través del Estado del Conocimiento sobre el tema "Relaciones Público-Privadas" en Educación (RPPE) en disertaciones de maestría y tesis doctorales desarrolladas en los Programas de Posgrado en Educación (PPGE) de la Brasil, de 1994 a 2018. Esta es una investigación exploratoria y cualitativa que también tuvo como objetivo comprender la evaluación atribuida por la Coordinación para la Mejora del Personal de Nivel Superior (CAPES) a los PPGE brasileños en el cuatrienio 2013-2016. para darse cuenta, el crecimiento del estudio de la temática RPPE en el posgrado brasileño con el fin de verificar algunas lagunas como la configuración de las producciones en la temática en cuestión.

\footnotetext{
${ }^{1}$ Universidade Estadual de Maringá - (UEM), Maringá - Paraná - Brasil. Graduanda em Ciências Biológicas pela Universidade Estadual de Maringá. Pesquisadora do Grupo de Estudos e Pesquisas em Políticas Educacionais, Gestão e Financiamento da Educação (GEPEFI/CNPq). ORCID: https://orcid.org/0000-0003-4570-2164. E-mail: marina_bonacazata@hotmail.com

${ }^{2}$ Universidade Estadual de Maringá - (UEM), Maringá - Paraná - Brasil. Mestre e Doutora em Educação pela Universidade Estadual de Maringá. Docente Adjunta do Programa de Pós-Graduação em Educação e do Departamento de Educação da Universidade Estadual de Maringá. Líder do Grupo de Estudos e Pesquisas em Políticas Educacionais, Gestão e Financiamento da Educação (GEPEFI/CNPq). Pós-Doutora em Educação pela Universidade Federal do Paraná (UFPR), com estágio pós-doutoral na Universidade de Salamanca (USA/ Espanha). ORCID: https://orcid.org/0000-0002-3008-0887. E-mail: professorajani@hotmail.com
} 
PALABRAS CLAVE: Estado del arte. Estado del conocimiento. Relaciones públicas y privadas. Programa de posgrado en educación. Brasil.

ABSTRACT: The aim of this study was mapping the bibliographic production on Public and Private Relations in Education (PPRE) through the State of Knowledge. This production comprises master's theses and doctoral dissertations produced in Postgraduation Programs in Education (PPGEs, Portuguese initials) in Brazil, from 1994 to 2018. This research, which is exploratory and qualitative, also aimed to understand the way the Coordination for the Improvement of Higher Education Personnel (CAPES) assessed the Brazilian PPGEs in the period from 2013 to 2016, as well as evidence the increase interest in studying the PPRE topic in Brazilian Graduate Programs in Education, in order to identify gaps regarding the configuration of the production related to it.

KEYWORDS: State of the art. State of knowledge. Public and private relations. Postgraduation programs in education. Brazil.

\section{Introdução}

O presente texto tem como objetivo mapear as produções sobre o tema Relação Público e Privado na Educação (RPPE) a fim de obter um panorama de como tem sido desenvolvida a temática nos Programas de Pós-Graduação em Educação no Brasil. Trata-se dos resultados de uma pesquisa qualitativa e bibliográfica, do tipo Estado do Conhecimento, no qual o foco foi a análise dissertações e teses na área da Educação.

Escolheu-se para a coleta dos dados a plataformas da Coordenação de Aperfeiçoamento de Pessoal de Nível Superior (CAPES) e a Biblioteca Digital Brasileira de Teses e Dissertações (BDTD), e nos bancos de dissertações e teses dos próprios PPGE, com recorte temporal no período de 1994-2018, visto que de acordo com o levantamento, no ano de 1994 foi identificada a primeira pesquisa referente ao tema.

A pesquisa do tipo Estado do Conhecimento se caracteriza por possuir um caráter bibliográfico, na qual se realiza um mapeamento de produções científicas referentes a um tema específico. Pesquisas que fazem uso dessa metodologia buscam:

[...] discutir uma certa produção acadêmica [...] tentando responder que aspectos e dimensões vêm sendo destacados e privilegiados em diferentes épocas e lugares, de que formas e em que condições tem sido produzidas certas dissertações de mestrado, teses de doutorado, publicações em periódicos e comunicações em anais de congressos e de seminários (FERREIRA, 2002, p. 257).

Os resultados visaram analisar a quantidade de PPGE brasileiros e sua relação com as respectivas avaliações atribuídas pela CAPES no quadriênio 2013-2016, além de verificar a 
distribuição dos PPGE por região do Brasil. Por fim, realizou-se um mapeamento das dissertações e teses dos PPGE brasileiros referentes à temática RPPE, no qual identificamos os seus temas e subtemas, a fim de perceber as nuances temáticas, aspectos metodológicos e teóricos dessa temática que tem sido crescente ao longo dos anos.

\section{Distribuição e avaliação dos programas de pós-graduação strictu senso em educação no Brasil}

Os primeiros PPG da área da Educação foram criados na década de 1960, em Instituições de Ensino Superior (IES) situadas na região sudeste, em particular, nos estados de São Paulo e Rio de Janeiro (WASSEM; PEREIRA; BALZAN, 2015, p. 217).

De acordo com informações da CAPES, hoje são aproximadamente 170 PPGE no Brasil. Os PPGE passaram de uma avaliação realizada a cada três anos para uma avaliação realizada a cada quatro anos, visando englobar os dados do Plano Nacional de Pós- Graduação do Brasil (2011-2020) (BRASIL, 2017).

Tendo como Base os dados disponibilizados pela CAPES extraídos da última avaliação quadrienal (2013-2016) (CAPES, 2018), analisamos 115 PPGEs. Foram excluídos das análises programas da área de Educação Tecnológica, Educação Ambiental, entre outros cujo propósito não é especificamente a Educação, sobretudo na linha de Políticas Públicas e Gestão da Educação ou Políticas Educacionais, dentre outros nomes semelhantes que denominam essa linha de pesquisa no Brasil.

Excluiu-se da análise também, os programas de mestrados e doutorados à distância e os mestrados e doutorados profissionais, ou seja, participaram da análise apenas os mestrados e doutorados acadêmicos.

Quanto à avaliação dos PPGE pela CAPES, é necessário destacar que critérios como a produção de artigos científicos, a distribuição de tal produção, a formação de mestres e doutores e a quantidade de mestres e doutores em cada programa são levados em consideração.

Quanto à atribuição das notas de cada programa, a CAPES adota uma escala numérica de sete pontos de 1 a 7. Nesta escala os conceitos 6 e 7 são exclusivos para programas de pósgraduação que ofereçam doutorado com nível de excelência de acordo com padrões de qualidade internacionais (WASSEM; PEREIRA; BALZAN, 2015, p. 218).

Dos 115 PPGE que foram coletados, obteve-se 24 programas com nota 3 , a nota 4 foi atribuída a 48 programas, 35 obtiveram nota 5 na avaliação, 6 programas tiveram a nota 6 e 
somente 2 programas obtiveram nota 7, que é a avaliação máxima. Os dados estão expostos na figura abaixo:

Figura 01 - Avaliação CAPES no quadriênio 2013-2016 para os PPGE

Fonte: Brasília - CCS/Capes. (Elaborado pela autora, 2019).

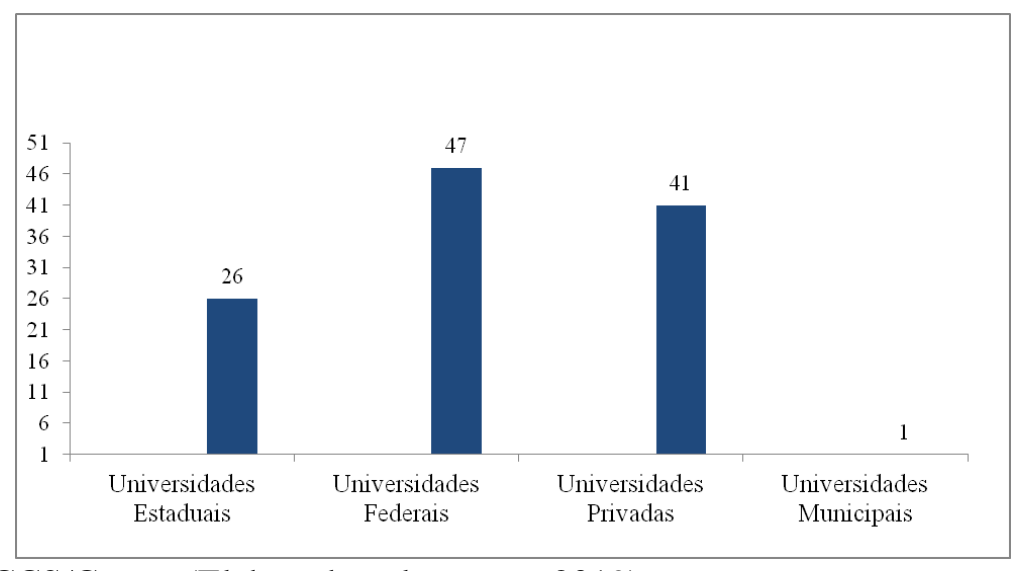

Quanto à esfera das universidades em que os PPGE se encontram, observou-se que 26 programas fazem parte de universidades estaduais, 48 são de universidades federais, 41 PPGE de universidades privadas e 1 de universidade municipal, como ilustra a figura 2 , a seguir:

Figura 2 - Distribuição dos PPGE em universidades estaduais, federais, privadas e municipais.

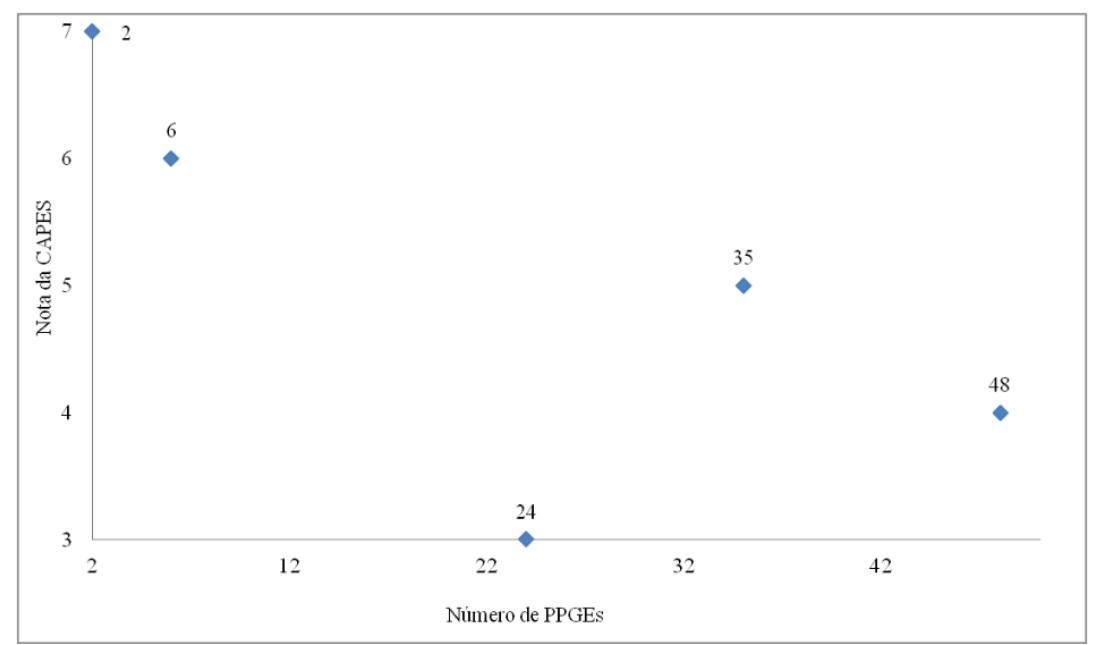

Fonte: Brasília - CCS/Capes. (Elaborado pela autora, 2019).

Utilizando o modelo de classificação de Araújo (2017), as universidades privadas foram agrupadas em subclassificações.

1) Universidades sem fins lucrativos (comunitárias, filantrópicas e confessionais) conveniadas com o poder público estadual e /ou municipal. 
2) Universidades sem fins lucrativos não conveniadas com o poder público.

3) Universidades privadas cujo mantenedor é uma empresa, grupo empresarial ou pessoa física e que possui fins lucrativos.

Os resultados obtidos estão expostos na figura abaixo:

Figura 3 - Divisão das universidades privadas

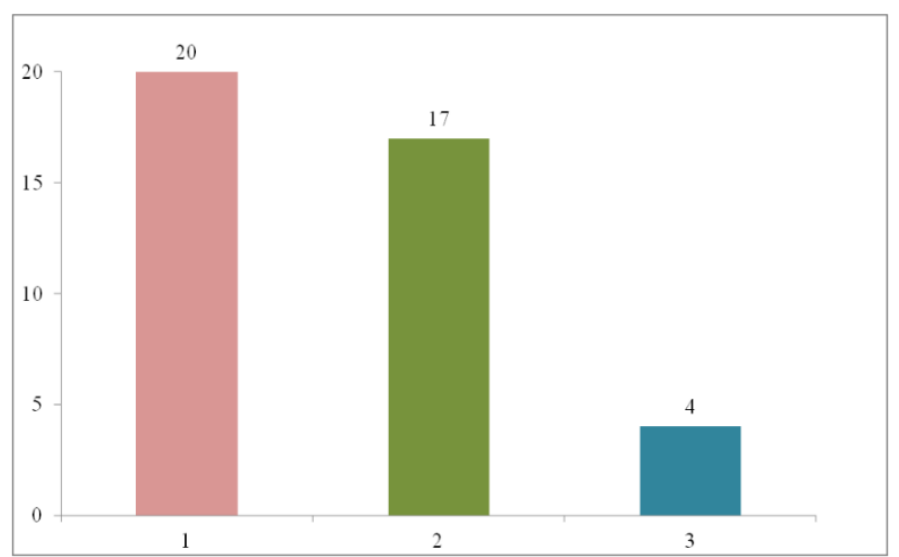

Fonte: Brasília - CCS/Capes; Araújo (2017, p. 77). (Elaborado pela autora, 2019).

Como é possível observar, a maioria das universidades privadas são financiadas pelo poder público estadual ou municipal, totalizando 20 . O gráfico também mostra, que 17 das universidades privadas não são financiadas pelo poder público e, por fim, se colocam as universidades privadas que são financiadas por empresas ou por pessoas físicas.

Um ponto a se destacar, é que a maioria dos programas avaliados com a nota 3 pela CAPES, aparecem nas universidades federais, assim como os que são avaliados com as notas 5 e 6. Os que receberam a nota 4 são a maior parte de universidades privadas.

Com relação às universidades estaduais, a maioria foi avaliada com nota 5, tendo uma com a nota 6 e uma com a nota máxima 7, como é mostrado na figura a seguir: 
Figura 4 - Esfera pública das universidades e as notas da CAPES no quadriênio 2013-2016

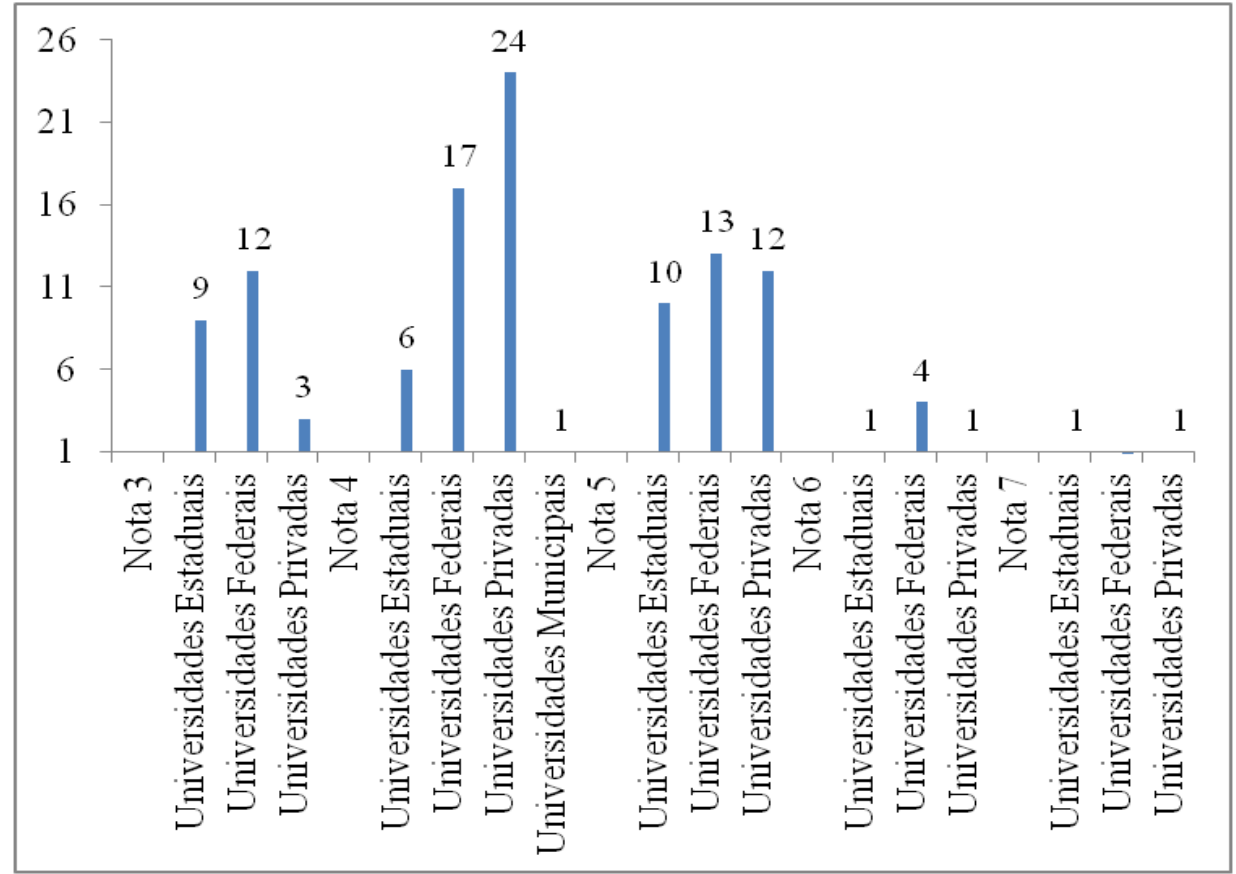

Fonte: Brasília - CCS/Capes. (Elaborado pela autora, 2019).

Um fator que despertou a atenção foi a distribuição de PPGEs de acordo com as regiões brasileiras. Em 2014, a CAPES destacou que a maior parte dos Programas de Pós-Graduação (PPG), 46,2\% se encontravam na região sudeste, mais precisamente no estado de São Paulo (WASSEM; PEREIRA; BALZAN, 2015, p. 217). No quadriênio 2013-2016, a situação permaneceu a mesma, como ilustra a figura 5, a seguir:

Figura 5 - Mapa 01: Distribuição dos Programas de Pós-Graduação em Educação por região do Brasil

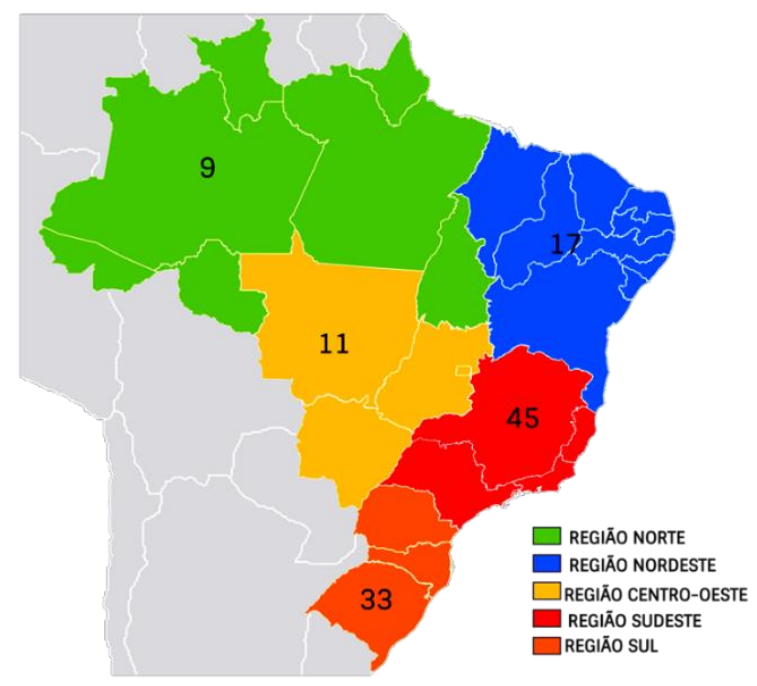

Fonte: Brasília - CCS/Capes. (Elaborado pela autora, 2019). 
Percebe-se pelo mapa acima, que a região Sudeste sustenta a maior parte dos PPGE (45), seguida pela região Sul (33), Nordeste (17), Centro-Oeste (11) e, por último, a região Norte (9).

Se levarmos em consideração a distribuição de PPGEs por estado do país, percebe-se que o estado de São Paulo apresenta a maior parte dos PPGEs (24), logo em seguida aparece o Rio Grande do Sul (13), Minas Gerais (12), Santa Catarina (11) e Paraná (9). O Paraná se encontra de coloração diferente na figura 6 , pois é o estado onde foi realizado o presente trabalho.

Figura 6 - Estados brasileiros com maior número de PPGE

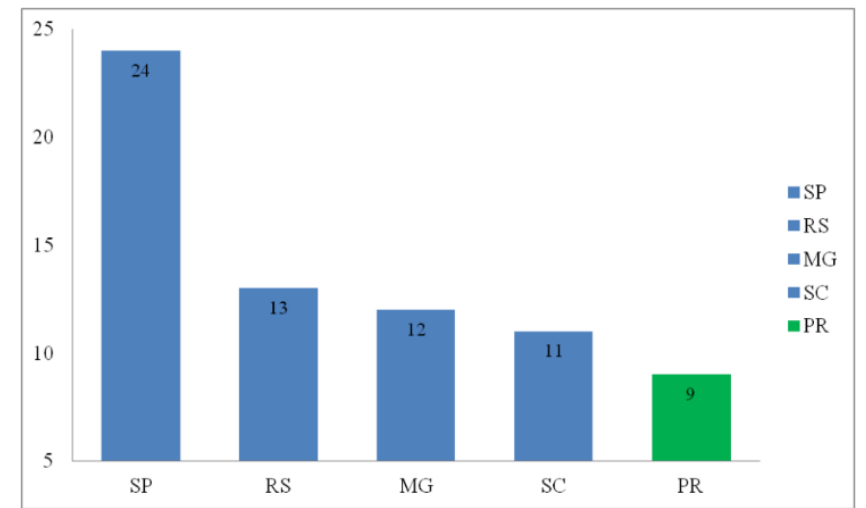

Fonte: Brasília - CCS/Capes. (Elaborado pela autora, 2019).

Vale ressaltar que é visível que os estados brasileiros possuem distribuição de renda e oportunidades desiguais, o que afeta a pós-graduação. Bittar et al. (2004) chamam a atenção para a disparidade de programas de pós-graduação e de sua produção científica, bem como para a preocupação com sua qualidade.

É importante mencionar que, por lógica, quanto mais desenvolvido é o estado, mais incentivo econômico ele recebe e, por conseguinte, melhores profissionais para seus programas de pós-graduação são contratados, o que reflete na qualidade dos programas.

O tempo de surgimento das universidades também se torna relevante para o desenvolvimento da pós-graduação. Como destacam Balbachevsky (1995) e Saviani (2002), a pós-graduação e sua produção científica permaneceram restritas a algumas "ilhas de competência" ou “centros de excelência", por exemplo, os estados de São Paulo e Rio de Janeiro. 


\section{Mapeamento do objeto de pesquisa "relação público-privado" e estudo do tipo de metodologias utilizadas nas produções científicas}

Para a realização do mapeamento do objeto de pesquisa, foi feita uma análise na plataforma de dissertações e teses da CAPES, na plataforma da Biblioteca Digital Brasileira de Teses e Dissertações (BDTD) e nos bancos de dissertações e teses dos Programas de PósGraduação em Educação do Brasil, foram encontradas 209 dissertações e teses que tratam do objeto "Relação Público-Privado".

Os temas e subtemas foram separados por meio da leitura do resumo de cada pesquisa, e as pesquisas que apresentaram no título ou nas palavras-chave do resumo alguma menção referente à Relação Público-Privado foram listadas. Foi possível observar que o maior número de produções referente ao tema ocorreu nos mestrados em educação, como destaca a figura 7 , abaixo:

Figura 7 - Distribuição das Dissertações e Teses sobre o objeto de pesquisa "Relação Público-Privado" (1994-2018).

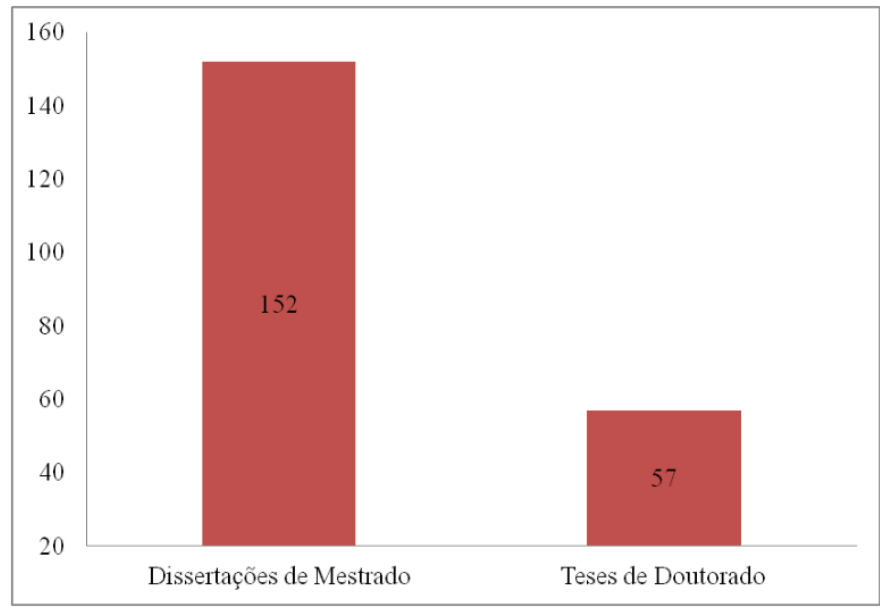

Fonte: Elaborado pela autora, 2019.

A análise dos PPGEs permitiu concluir que no período de 1994-2018, a universidade que mais produziu dissertações e teses referentes ao objeto de pesquisa foi a Universidade Estadual Paulista "Júlio de Mesquita Filho" (UNESP). A Universidade Estadual de Maringá (UEM), sede do presente trabalho, teve cinco pesquisas e aparece de coloração diferenciada na figura 8, a seguir: 
Figura 8 - PPGE das universidades que mais produziram dissertações e teses sobre o objeto "Relação Público-Privado"

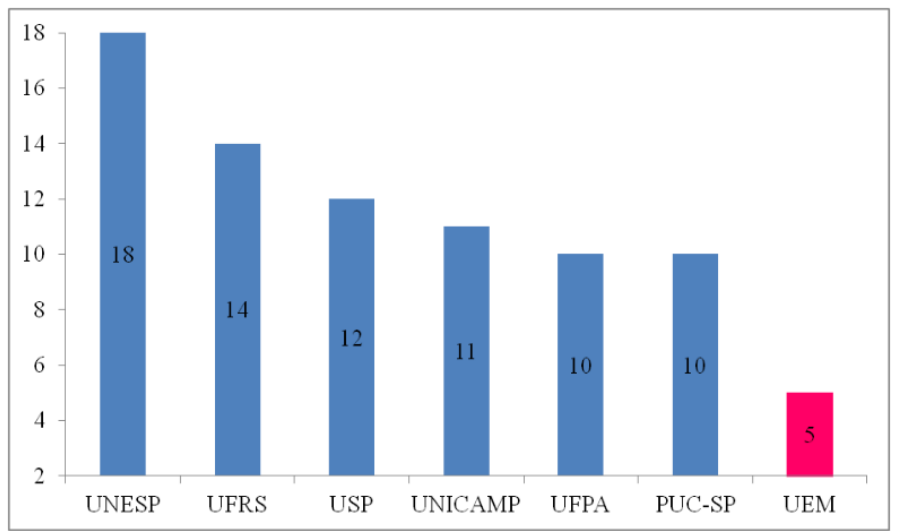

Fonte: Elaborado pela autora, 2019.

A presente pesquisa fez um estudo das metodologias utilizadas pelos autores nas suas dissertações e teses sobre o objeto de pesquisa "Relação Público-Privado". Já foi mencionado anteriormente que a pesquisa do tipo estado do conhecimento é de fonte bibliográfica.

A pesquisa bibliográfica ou de fontes secundárias, segundo Marconi e Lakatos (2003, p. 183), abrange toda a bibliografia já tornada pública em relação ao tema de estudo, desde publicações avulsas, boletins, jornais, revistas, livros, pesquisas, monografias, teses, material cartográfico, etc., até meios de comunicações orais: rádios, gravações em fita magnética e audiovisuais: filmes e televisão.

As autoras afirmam que a pesquisa bibliográfica pode ser documental. A pesquisa documental apresenta arquivos públicos ou particulares. Os arquivos públicos podem ser: municipais, estaduais e nacionais e em sua maior parte contém documentos oficiais tais como: ordens, régias, leis, ofícios, relatórios, correspondências anuários, alvarás e etc. Publicações parlamentares como: Atas, debates, documentos, projetos de lei impressos, relatórios e etc.

Por outro lado, as pesquisas bibliográficas também podem ser de campo. Para Tripodi et al., (1975, p. 42-71), as pesquisas de campo dividem-se em três grandes grupos: Quantitativodescritivos, exploratórios e experimentais:

A) Quantitativo-Descritivo - Consistem de investigações de pesquisa empírica, cuja a principal finalidade é o delineamento ou análise das características de fatos ou fenômenos, a avaliação de programas ou o isolamento de variáveis principais ou chave. Qualquer um desses estudos pode utilizar métodos formais, que se aproximem dos projetos experimentais, caracterizados pela precisão e controle estatísticos, com a finalidade de fornecer dados para a verificação de hipóteses. Todos eles empregam artifícios quantitativos tendo por objetivo a 
coleta sistemática de dados sobre populações, programas ou amostras de populações. Utilizam várias técnicas como entrevistas, questionários, formulários, etc. e empregam procedimentos de amostragem.

B) Exploratórios - São investigações de pesquisa empírica cujo objetivo é a formulação de questões ou de um problema com tripla finalidade: desenvolver hipóteses, aumentar a familiaridade do pesquisador com um ambiente, fato ou fenômeno, para a realização de uma pesquisa futura mais precisa ou modificar e clarificar conceitos, empregando-se geralmente procedimentos sistêmicos ou para a obtenção de observações empíricas ou para as análises de dados (ou ambas simultaneamente). Obtém-se frequentemente descrições tanto quantitativas quanto qualitativas do objeto de estudo e o investigador deve conceituar as interrelações entre as propriedades do fenômeno, fato ou ambiente observado. Uma variedade de procedimentos de coleta de dados pode ser utilizada, como entrevista, observação-participante, análise de conteúdo, etc., para o estudo relativamente intensivo de um pequeno número de unidades, mas geralmente sem o emprego de técnicas probabilísticas de amostragem. Muitas vezes ocorre a manipulação de uma variável independente coma finalidade de descobrir seus efeitos potenciais.

C) Experimentais - Consistem em investigações de pesquisa empírica cujo objetivo principal é o teste de hipóteses que dizem respeito a relações de tipo causa-efeito. Todos os estudos desse tipo utilizam projetos experimentais que incluem os seguintes fatores: grupos de controle (além do experimental), seleção da amostra por técnica probabilística e manipulação das variáveis independentes com a finalidade de controlar ao máximo os fatores pertinentes. As técnicas rigorosas de amostragem têm o objetivo de possibilitar a generalização das descobertas a que se chega pela experiência. Por sua vez, para que possam ser descritas quantitativamente, as variáveis relevantes são especificadas. Os diversos tipos de estudos experimentais podem ser desenvolvidos tanto "em campo", ou seja, no ambiente natural, quanto em laboratório, onde o ambiente é rigorosamente controlado.

\section{Estudo do estado de conhecimento do objeto de pesquisa "relação público-privado"}

Para a realização do estudo do Estado de Conhecimento do objeto proposto, apresentaremos os aspectos evidenciados a partir dos seguintes eixos de análise sobre o objeto: 1) Crescimento da produção 2) Distribuição da produção por região; 3) Aumento de subtemas.

1) Crescimento da produção: 
Figura 9 - Estado do Conhecimento do objeto de pesquisa "Relação Público-Privado" (19942018)

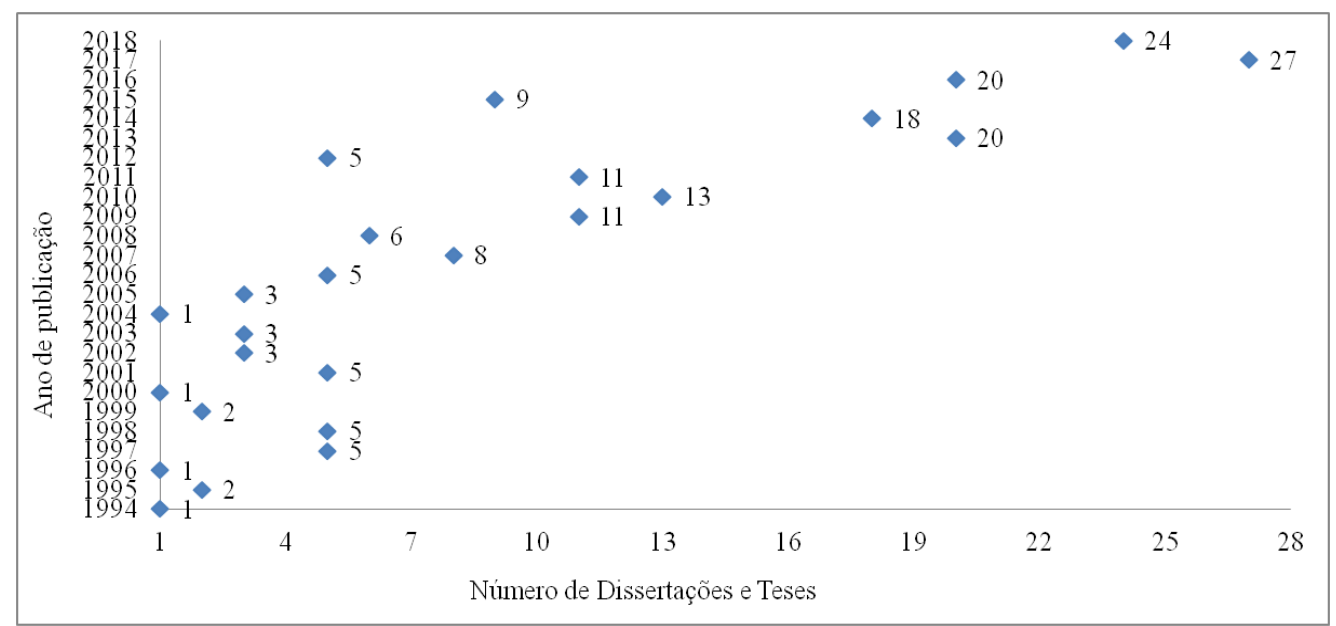

Fonte: Elaborado pela autora, 2019.

A figura acima revela um crescimento da produção a partir do ano de 1994, no qual apresentou apenas uma pesquisa relacionada ao tema RPPE. Nos anos de 2016, 2017 e 2018, foram encontrados 20, 27 e 24 pesquisas, respectivamente, portanto a partir de 2016, houve um crescimento mais expressivo da produção. A constatação do crescimento de pesquisas revelou que o tema tem sido gradativamente pesquisado e que isso também é consequência das mudanças na configuração das políticas educacionais a partir da década de 90.

2) Distribuição da produção por região:

Ao se observar a figura 10, o mapa abaixo, percebe-se que uma maior produção da temática ocorreu na região sudeste do Brasil, com 103 dissertações e teses e a menor produção ocorreu na região norte do país, com 14 produções. 
Figura 10 - Mapa 02: Distribuição das Dissertações e Teses sobre o objeto de estudo "Relação Público-Privado" por região do Brasil

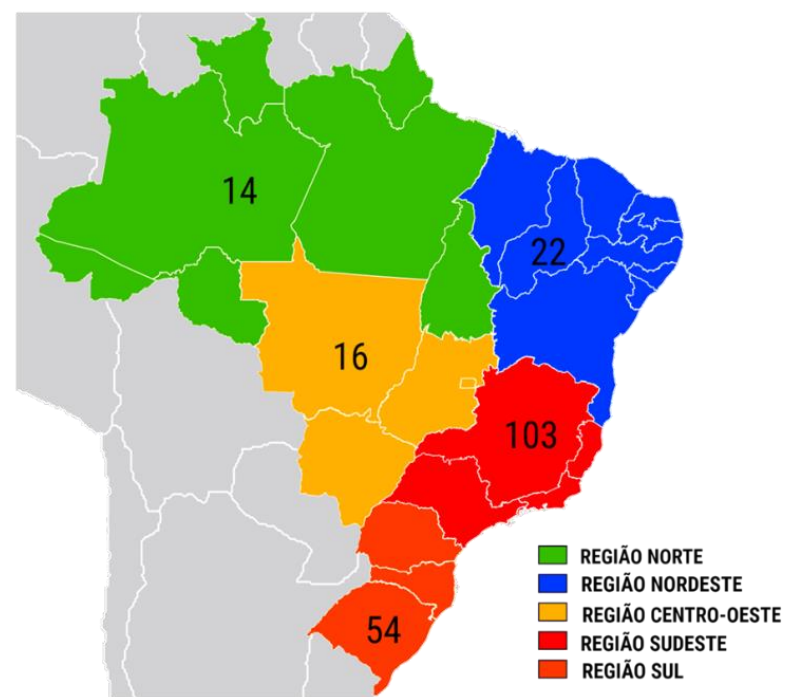

Fonte: Elaborado pela autora, 2019.

Pode-se concluir que, embora corresponda a uma pequena parcela da produção mundial, no que se refere à pesquisa científica, já se percebe que a produção brasileira apresenta graves distorções quando analisada a sua distribuição espacial regional (SÁ; MOURA; VASCONCELOS, 2007, p. 579).

Apenas para citar alguns exemplos, os autores afirmam que, a região sudeste concentra $66 \%$ dos grupos de pesquisa cadastrados no CNPq, enquanto a região nordeste conta com $12 \%$. O Sudeste é a região de maior destaque no cenário da pesquisa brasileira.

Como foi dito na seção 1, fica claro que temos uma distribuição de recursos irregular nas diferentes regiões do país, além da região sudeste ser uma região comercial muito forte para o Brasil, sendo, portanto, bem desenvolvida economicamente.

\section{Considerações finais}

Os resultados da pesquisa mostraram que pesquisas do tipo Estado do Conhecimento são fundamentais para o aprofundamento dos conhecimentos que são produzidos sobre um objeto de pesquisa ou um determinado tema, no caso da presente pesquisa, do tema "Relação Público e privado (RPPE) nos PPGEs.

Identificou-se que nos 115 programas de pós-graduação específicos em Educação, no quadriênio da CAPES (2013-2016), 24 obtiveram nota 3, a maioria dos programas foram avaliados com a nota 4 , totalizando 48 , e se localizam em maior número na região sudeste do 
país, com maior incidência nos estados de São Paulo e Rio Grande do Sul. Pode-se associar esse fato ao grande desenvolvimento e investimento que as regiões sudeste e sul apresentam em relação ao ensino superior, além de serem as pioneiras no campo da pós-graduação em Educação.

A nota 5 foi atribuída a 35 PPGE, enquanto as notas 6 e 7 foram mais discretas, já que apenas 6 dos PPGE receberam a nota 6 e apenas 2 deles receberam a nota máxima 7. Isso significa que o Brasil ainda possui poucos PPGE de excelência.

Com o mapeamento do objeto de estudo, percebeu-se que o maior número de produções se deu no intervalo dos anos 2016-2018. Foi possível identificar que de 1994 até 2018, foram totalizadas 152 dissertações de mestrado e 57 teses de doutorado que abordaram o tema RPPE.

A pesquisa também identificou que a região sudeste do Brasil apresenta o maior número das produções relacionadas ao tema RPPE e a região norte apresenta o menor número, visto que a distribuição das universidades é desigual no Brasil, pois o sudeste, onde se concentra o maior número de estudantes de ensino superior é a região com o maior investimento, além de ser uma forte região do comércio brasileiro, já a região norte apresenta menos alunos matriculados no ensino superior e por isso não recebe tanto investimento quando comparado à região sudeste.

Fica evidente a necessidade do desenvolvimento de pesquisas da temática nas diferentes regiões do país e a solidificação dos programas em Educação, o que envolve a efetivação e a construção de políticas para o Ensino Superior que priorizem o desenvolvimento e o investimento nos Programas de Pós-Graduação em Educação de forma equitativa nas cinco regiões brasileiras.

O tema RPPE foi mais abordado com o uso da metodologia bibliográfica e documental, de caráter exploratório, porém algumas pesquisas abordaram a análise de programas como PROUNI, FIES, SISU, programa de educação em tempo integral, e optaram por utilizar a metodologia quantitativa-descritiva.

Conclui-se que a temática RPPE vem sendo discutida de forma satisfatória, contudo ainda carece de ampliar discussões, pois a temática é ampla abrangendo gestão da educação, financiamento da educação, organismos internacionais, organizações sociais, formação de professores, entre outros subtemas, além de ser um tema relevante para a compreensão da construção, implementação e avaliação das políticas públicas educacionais no país. 


\section{REFERÊNCIAS}

ARAÚJO, L. Estado da relação da relação público e privado na educação básica. In: Público e Privado em tempos de Golpe. 1. ed. São Paulo: Fundação Lauro Campos, p. 77, 2017.

BALBACHEVSCKY, E. A pós-graduação no Brasil: novos desafios para uma política bemsucedida. In: BROCK. C.; SCHWARTZMAN, S. Os desafios da educação no Brasil. Rio de Janeiro: Nova Fronteira, p. 275-304, 2005.

BITTAR, M. et al. Educação Superior e o Projeto Universitas/BR: a descentralização da pesquisa no Brasil. In: BITTAR, M.; OLIVEIRA, J. F. (Orgs.). Gestão e políticas da educação. Rio de Janeiro: DP\&A, p. 141-155, 2004.

BRASIL. Portaria n. 59, de 21 de março de 2017. Dispõe sobre o regulamento da Avaliação Quadrienal. 2017. Disponível em:

https://capes.gov.br/images/stories/download/avaliacao/27032017-Portaria-59-21-03-2017-

Regulamento-da-Avaliacao-Quadrienal.pdf. Acesso em: 17 de agosto 2019.

COORDENAÇÃO DE APERFEIÇOAMENTO PESSOAL DE NÍVEL SUPERIOR -

CAPES. Avaliação da CAPES aponta crescimento da pós-graduação brasileira - 2018 .

Disponível em: http://www.capes.gov.br/sala-de-imprensa/noticias/8558-avaliacao-da-capes-

aponta-crescimento-da-pos-graduacao-brasileira. Acesso em: 17 ago. 2019.

FERREIRA, N. S. de. A. As pesquisas denominadas “estado da arte". Educação \&

Sociedade, ano XXIII, n. 79, p. 257-272, ago. 2002.

MARCONI, M. de. A; LAKATOS, E. M. Fundamentos de Metodologia Científica. 5. ed. São Paulo: Atlas, 2003.

SÁ, L. A. C. M. de.; MOURA, A. L. A. de.; VASCONCELOS, T. L. Mapeamento do Ensino Superior e Pesquisa no Brasil. II Simpósio Brasileiro de Geomática e V Colóquio

Brasileiro de Ciências Geodésicas, Presidente Prudente - SP. 2007. Disponível em: http://docs.fct.unesp.br/departamentos/cartografia/eventos/2007_II_SBG/artigos/A_083.pdf. Acesso em: 17 de agosto, 2019.

SAVIANI, D. A pós-graduação em educação no Brasil: pensando o problema da orientação. In: BIANCHETTI, L. et al (Orgs.). A bússola do escrever: desafios e estratégias na orientação de teses e dissertações. Florianópolis: UFSC, p. 135-163, 2002.

TRIPODI, T. et al. Análise da pesquisa social: diretrizes para o uso de pesquisa em serviço social e em ciências sociais. Rio de Janeiro: Francisco Alves, 1975.

WASSEM, J.; PEREIRA, E. M. de A.; BALZAN, N. C. Política de avaliação em programas de pós-graduação de excelência em educação. Atos de Pesquisa em Educação, v. 10, n. 1, p. 215-243, jan./abr. 2015. 


\section{Como referenciar este artigo:}

SANTOS, Marina Silveira Bonacazata; MOREIRA, Jani Alves da Silva. Estado do conhecimento da temática relação público e privado nos programas de pós-graduação strictu senso em educação no Brasil. Revista on line de Política e Gestão Educacional, Araraquara, v. 24 n. 1 , p. 117-131, jan./abr., 2020. e-ISSN: 1519-9029. DOI: https://doi.org/10.22633/rpge.v24i1.12895

Submetido em: 30/05/2019

Revisões requeridas: $15 / 10 / 2019$

Aprovado em: 30/11/2019

Publicado em: 06/01/2020 